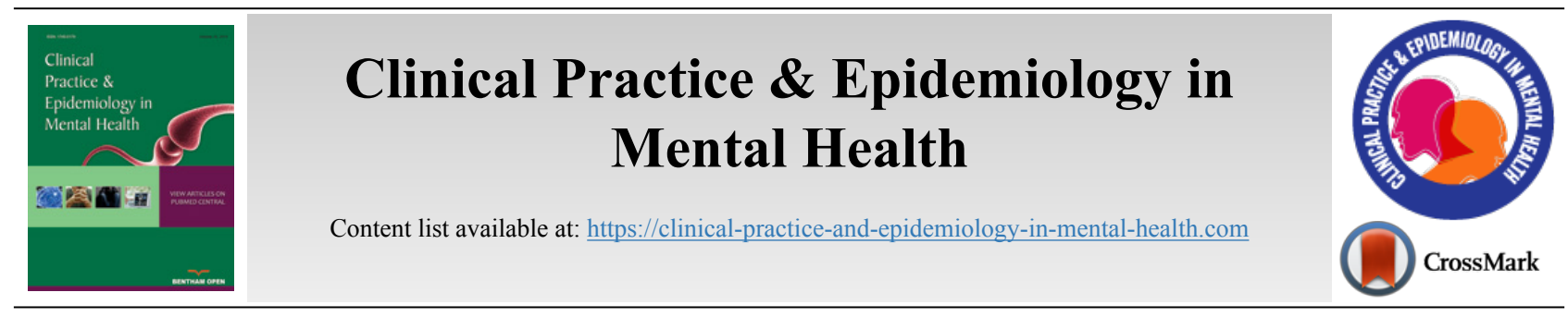

RESEARCH ARTICLE

\title{
Patterns and Predictors of Internet Gaming Disorder: An Observational Study from Jordan
}

\author{
Reema Karasneh ${ }^{1}$, Sayer Al-Azzam ${ }^{2}$, Karem H. Alzoubi ${ }^{3,4, *}$, Mohammad B. Nusair ${ }^{5}$, Sahar Hawamdeh ${ }^{2}$ and Amal T. \\ Nusir $^{6}$ \\ ${ }^{l}$ Department of Basic Medical Sciences, Faculty of Medicine, Yarmouk University, Irbid, Jordan \\ ${ }^{2}$ Department of Clinical Pharmacy, Faculty of Pharmacy, Jordan University of Science and Technology, Irbid, Jordan \\ ${ }^{3}$ Department of Pharmacy Practice and Pharmacotherapeutics, University of Sharjah, Sharjah, UAE \\ ${ }^{4}$ Faculty of Pharmacy, Jordan University of Science and Technology, Irbid, Jordan \\ ${ }^{5}$ Department of Clinical Pharmacy and Pharmacy Practice; Faculty of Pharmacy, Yarmouk University, Irbid, Jordan \\ ${ }^{6}$ Department of Arabic Language and Literature, Faculty of Arts, Yarmouk University, Irbid, Jordan
}

\begin{abstract}
:
Objective:

Internet Gaming Disorder (IGD) is a rapidly growing public health problem that may have detrimental effects. The purpose of this study is to identify factors associated with IGD status.

Methods:

In this cross-sectional observational study, a convenient sample of gamers in Jordan was recruited and asked to participate in an online survey based on the nine criteria of the 20-item Internet Gaming Disorder (IGD-20) used to assess gaming disorder. Sociodemographic and psychosocial data were also obtained.

Results:

A total of 504 gamers participated in this study. The mean age of respondents was $21.6 \pm 3.90$ years. Using the standard IGD-20 scale, 96 participants $(19 \%)$ were classified as potential IGD cases, compared to $408(80.9 \%)$ non-disordered gamers. Males were dominant among the population, constituting $348(69 \%)$ of gamers. Males also played significantly more hours per week [17.8 \pm 16.75$]$ compared to females [13 \pm 17.65]. The majority of gamers $(411(81.5 \%))$ were students, although unemployed adults played for the highest total time [23.9 \pm 30.84 hours/week]. Device type used for gaming also significantly $(\mathrm{p}<0.05)$ affected the time spent playing. Predictors of IGD included educational level $(\mathrm{p}<0.05)$ and playing hours/week $(\mathrm{p}<005)$. Conversely, no significant associations were found between IGD and gender, age, employment, or sleeping hours. IGD is increasingly being diagnosed among both genders and presents a health challenge for internet users.

Conclusion:

Establishing gamer profiles and recognizing predictors of IGD is therefore vital for guiding clinical classification and diagnosis of the disease.
\end{abstract}

Keywords: Gaming, IGD, Patterns, Mental disorders, Impairment, Addiction, Relapse, Psychosocial data.

\begin{tabular}{|l|l|l|l|}
\hline Article History & Received: June 25, 2021 & Revised: September 1, 2021 & Accepted: October 12, 2021
\end{tabular}

\section{INTRODUCTION}

The technological advances of the last decades provided humans with a myriad of accessible and pleasurable gaming options. However, the introduction of internet gaming addic-

\footnotetext{
* Address correspondence to this author at Clinical Pharmacy, Jordan University of Science and Technology, Irbid and Department of Basic Medical Sciences, Faculty of Medicine, Yarmouk University, Irbid-Jordan; Tel: +962 (02) 7211111; Fax:+962 (02) 7211162; E-mails: khalzoubi@just.edu.jo,

reema.karasneh@yu.edu.jo
}

tion in the Diagnostic and Statistical Manual of Mental Disorders, Fifth Edition (DSM-5) sparked controversy regarding the classification of certain gaming behaviours under 'non-substance addictive behaviours [1,2].

Internet gaming disorder (IGD) the problematic use of computer games (whether online or offline)- has become a significant public health concern. Several studies have reported that IGD is comorbid with several other disorders and mental health issues, including impairment of personal and social 
functioning [2 - 4]. The DSM-5 has defined IGD as "persistent and recurrent use of the Internet to engage in games, often with other players, leading to clinically significant impairment or distress." [5]. In addition, the WHO has defined gaming disorder in the latest beta draft version of the 11th revision of the International Classification of Diseases (ICD-11) as a new disorder [6]. After DSM-5 diagnosis of Internet Gaming Disorder (IGD), several studies have investigated its prevalence and factors that may be associated with its diagnosis and severity.

Variations in IGD prevalence rates were found among different populations and may be attributed to different tools used for IGD assessment and different cut-offs [7]. Several tools were developed for IGD assesment; however, the IGD-20 test was the first to assess IGD according to the nine criteria suggested by the American Psychiatric Association in the latest edition of the DSM-5 [8]. Worldwide, the prevalence of IGD ranged between $0.2 \%$ and $8.5 \%$; the highest prevalence was estimated in the Korean population, with $50 \%$ of the population found to be addicted to gaming [9 - 11]. In a recent metaanalysis of 16 studies that investigated IGD prevalence among adolescents, the pooled prevalence of IGD was $4.6 \%$ (95\% CI $=3.4 \%-6.0 \%$ ) with higher prevalence rate reported in male adolescents $(6.8 \%, 95 \%$ CI $=4.3 \%-9.7 \%)$ than female adolescents $(1.3 \%, 95 \% \mathrm{CI}=0.6 \%-2.2 \%)$ [12]. Additionally, in a recent cross-sectional survey that has investigated IGD in European adolescents, $1.6 \%$ were diagnosed with IGD, with a further $5.1 \%$ being at risk for IGD. Among Europeans, IGD was highly associated with aggressive and rule-breaking behaviour and social problems [13]. Several factors were associated with IGD diagnosis, including male gender, age, poor self-esteem, and daily life satisfaction [13 - 16]. A recent systematic review by Mihara and Higuchi that included 37 cross-sectional and 13 longitudinal studies reported that IGD was associated with longer time spent playing games, higher frequency of playing games, more years playing games, and family and marital factors. Consequences related to IGD diagnosis included lower educational and career attainment (lower school grades, skipped school classes, and truancy), lower social skills, competence, and integration, in addition to higher impulsivity, neuroticism, aggression and violence [17].

In Jordan and the middle east area, studies are scarce about IGD. There is no account about IGD prevalence or profile of those with this disorder. Only a single study from the United Arab Emirates showed that IGD was associated with symptoms of mood disorder that worsen overtime. Thus, the current study came to establish a profile of disordered and non-disordered gamers and identifies the prevalence of IGD among adolescent and adult gamers. It also recognizes factors associated with an increased risk of IGD. Our study aims to and examines factors associated with IGD in the Jordanian population.

\section{METHODS}

\subsection{Participants}

Participants were recruited using online social media applications. All participants who completed the questionnaire were included.

\subsection{Measures}

The main questionnaire consisted of three sections: the first includes socio-demographic characteristics such as age, height, weight, sex, social status, education level, occupation, sleeping hours and the presence of chronic diseases. Respondents were inquired about their use of internet games within the preceding year. The second part inquired about the amount of daily play and used devices. Computer gaming behavior was assessed with a translated and validated Arabic version of the IGD-20 questionnaire [2].

\section{IGD-20 Scale}

The IGD-20 scale reflects the nine criteria of IGD, and it is based on the DSM-5 guidance and incorporates the theoretical framework of the components model of addiction [18]. Participants rated the 20 items on a 5-point Likert scale: 1 ("strongly disagree"), 2 ("disagree"), 3 ("neither agree nor disagree"), 4 ("agree"), and 5 ("strongly agree"). Participants were classified into two groups: disordered (Internet Gaming Disorder Group (IGDG; scoring 71 or more on the IGD-20)) and non-disordered or casual gaming group (CGG; scoring below 71 on the IGD-20) gamers. The use of a 71 cut-off point to diagnose IGD was proposed in an earlier study where it obtained adequate sensitivity and specificity [8].

\subsection{Procedures}

This is a descriptive, questionnaire-based study with a cross-sectional design. The questionnaire was distributed nationwide in Jordan using an online survey on social media based on voluntary participation. A brief description about the purpose of the study was provided.

\subsection{Statistical Analysis}

Statistical analyses comprised (i) descriptive statistical analysis of the main sample's characteristics, (ii) chi-square test, independent and paired samples student's t-test for mean comparisons for identifying possible significant group effects of the variables involved in this study on Internet usage and characteristics, and (iii) correlational analyses of the main variables included in the study using IBM SPSS Statistics Version 23.

\subsection{Ethics}

A brief description of the study was provided to participants prior to their participation. Participants were also informed prior to their participation that it would be completely anonymous, and no identifiable data will be obtained to reduce social desirability bias. Participation was completely voluntary and written informed consents were obtained from all study participants. Ethical approval for conducting the study was obtained from the institutional review board (reference code $32 / 119 / 2018$ ). The study procedures were carried out in accordance with the Declaration of Helsinki.

\section{RESULTS}

Table 1 shows study participant demographics. A total of 504 participants enrolled in our study. Males were dominant $348(69 \%)$ compared to females 156 (31\%). The overwhelming 
majority of study subjects were students $411(81.5 \%)$ with a mean age of $21.6 \pm 3.90$ years. Devices used for gaming varied between smartphones 380 (75.4\%), a personal computer 177 (35.1\%), a video game console such as PlayStation or Xbox $137(27.2 \%)$, and tablets 38 (7.5\%). Participants spent an average of $16.3 \pm 17.28$ hours per week playing (Table $\mathbf{1}$ ).

There was a significant association between playing hours per week and gender ( $\mathrm{P}$ value $<0.005$ ), as males were more likely to spend more hours playing than females. Employment status also affected total playing time, as unemployed gamers invested more time playing $(23.9 \pm 30.84 \mathrm{hrs} /$ week playing $)$ compared to students $(16 \pm 15.54 \mathrm{hrs} /$ week $)$ and employed gamers (13.4 $\pm 15.95 \mathrm{hrs} /$ week $)$. Using a computer compared to a tablet, smart phone, or gaming console was positively associated with more playing hours ( $\mathrm{P}$ value $<0.041$ ).

Difference was also assessed between disordered $(n=96$ $(19 \%))$, and non-disordered gamers $(\mathrm{n}=408(80.9 \%))$ (Table 2$)$. There were no significant differences between disordered and non-disordered gamers in age, body mass index, sleeping hours, gender, or marital status. However, playing hours/ week $(\mathrm{p}<0.005)$ and educational level $(\mathrm{p}<0.05)$ were significantly higher among disorder gamers.

Table 1. Participants socio-demographic characteristics $(n=504)$.

\begin{tabular}{|c|c|c|c|c|}
\hline \multicolumn{2}{|c|}{ Demographic Variables } & \multirow{2}{*}{\begin{tabular}{|c|} 
Frequency (\%) \\
$348(69 \%)$ \\
\end{tabular}} & \multirow{2}{*}{\begin{tabular}{|c|}
$\begin{array}{c}\text { Playing Hours/Week } \\
(\text { mean } \pm \text { SD) }\end{array}$ \\
$17.8 \pm 16.75$ \\
\end{tabular}} & \multirow{2}{*}{\begin{tabular}{|l|} 
P value \\
$<0.005$ \\
\end{tabular}} \\
\hline Gender & Male & & & \\
\hline & Female & $156(31 \%)$ & $13 \pm 17.65$ & \\
\hline \multirow[t]{3}{*}{ Education } & Up to secondary level & $72(14.3 \%)$ & $19.3 \pm 17.95$ & \multirow[t]{3}{*}{.274} \\
\hline & Bachelor's degree or diploma & $420(83.3 \%)$ & $15.9 \pm 17.29$ & \\
\hline & Post-graduate degree & $12(2.4 \%)$ & $13.8 \pm 10.89$ & \\
\hline \multirow[t]{3}{*}{ Employment } & Employed & $56(11.1 \%)$ & $13.4 \pm 15.95$ & \multirow[t]{3}{*}{.012} \\
\hline & Unemployed & $37(7.3 \%)$ & $23.9 \pm 30.84$ & \\
\hline & Student & $411(81.5 \%)$ & $16 \pm 15.54$ & \\
\hline \multirow[t]{2}{*}{ Martial Status } & Single & $484(96 \%)$ & $16.1 \pm 16.21$ & \multirow[t]{2}{*}{.134} \\
\hline & Married & $20(4 \%)$ & $22 \pm 34.30$ & \\
\hline \multirow[t]{2}{*}{ Chronic Conditions } & No & $483(95.8 \%)$ & $16.4 \pm 17.23$ & \multirow[t]{2}{*}{.700} \\
\hline & Yes & $21(4.2 \%)$ & $14.9 \pm 18.61$ & \\
\hline \multirow[t]{4}{*}{ Device(s) used for gaming } & Smart phone & $380(75.4 \%)$ & $15.8 \pm 16.46$ & \multirow[t]{4}{*}{.041} \\
\hline & Computer & $177(35.1 \%)$ & $20.1 \pm 18.05$ & \\
\hline & Tablet & $38(7.5 \%)$ & $14.4 \pm 16.22$ & \\
\hline & Video game console (PlayStation, Xbox... etc.) & $137(27.2 \%)$ & $16.2 \pm 17.35$ & \\
\hline \multicolumn{3}{|c|}{ Age $($ mean \pm SD) } & \multicolumn{2}{|l|}{$21.6 \pm 3.90$} \\
\hline \multicolumn{3}{|c|}{ Body Mass Index (mean \pm SD) } & \multicolumn{2}{|l|}{$24.9 \pm 8.81$} \\
\hline \multicolumn{3}{|c|}{ Sleeping hours $($ mean $\pm \mathrm{SD})$} & \multicolumn{2}{|l|}{$7.7 \pm 1.75$} \\
\hline \multicolumn{3}{|c|}{ Playing hours/week (mean $\pm \mathrm{SD}$ ) } & \multicolumn{2}{|l|}{$16.3 \pm 17.28$} \\
\hline
\end{tabular}

Table 2. Association between gaming disorder status and sociodemographic parameters.

\begin{tabular}{|c|c|c|c|}
\hline- & $\begin{array}{c}\text { Disordered Gamers (n=96) } \\
\text { Frequency (\%) }\end{array}$ & $\begin{array}{c}\text { Non-disordered Gamers (n=408) } \\
\text { Frequency (\%) }\end{array}$ & P value \\
\hline Gender & - & - & - \\
\hline Male & $62(17.8 \%)$ & $286(82.2 \%)$ & 0.326 \\
\hline Female & $34(21.8 \%)$ & $122(78.2 \%)$ & - \\
\hline Marital Status & - & - & - \\
\hline Single & $94(19.4 \%)$ & $390(80.6 \%)$ & 0.393 \\
\hline Married & $2(10 \%)$ & $18(90 \%)$ & - \\
\hline Education level & - & - & 0.044 \\
\hline Up to secondary level & $21(29.2 \%)$ & $51(70.8 \%)$ & - \\
\hline Bachelor's degree or diploma & $74(17.6 \%)$ & $346(82.4 \%)$ & - \\
\hline Post-graduate & $1(8.3 \%)$ & $11(91.7 \%)$ & - \\
\hline Employment & - & - & \\
\hline Student & $79(19.2 \%)$ & $332(80.8 \%)$ & 0.622 \\
\hline Employed & $12(21.4 \%)$ & $44(78.6 \%)$ & - \\
\hline Unemployed & $5(13.5 \%)$ & $32(86.5 \%)$ & - \\
\hline Age & $21.4 \pm 4.87$ & $21.6 \pm 3.65$ & 0.731 \\
\hline
\end{tabular}


(Table 2) contd.....

\begin{tabular}{|c|c|c|}
\hline- & $\begin{array}{c}\text { Disordered Gamers (n=96) } \\
\text { Frequency (\%) }\end{array}$ & $\begin{array}{c}\text { Non-disordered Gamers (n=408) } \\
\text { Frequency (\%) }\end{array}$ \\
\hline Body mass index & $24.9 \pm 6.58$ & $24.8 \pm 9.27$ \\
\hline Sleeping hours & $8.0 \pm 1.72$ & 0.979 \\
\hline Playing hours/week & $22.6 \pm 20.47$ & 0.080 \\
\hline
\end{tabular}

Table 3. Frequency of IGD-20 items among participants.

\begin{tabular}{|c|c|c|c|c|c|}
\hline Item & Strongly Agree & Agree & $\begin{array}{c}\text { Neither agree or } \\
\text { disagree }\end{array}$ & Disagree & Strongly Disagree \\
\hline I often lose sleep because of long gaming sessions. & $28(5.6 \%)$ & $124(24.6 \%)$ & $130(25.8 \%)$ & $138(27.4 \%)$ & $84(16.7 \%)$ \\
\hline $\begin{array}{l}\text { I usually think about my next gaming session when I am not } \\
\text { playing }\end{array}$ & $23(4.6 \%)$ & $141(28 \%)$ & $94(18.7 \%)$ & $149(29.6 \%)$ & $97(19.2 \%)$ \\
\hline $\begin{array}{l}\text { I think gaming has become the most time-consuming activity in } \\
\text { my life }\end{array}$ & $64(12.7 \%)$ & $169(33.5 \%)$ & $62(12.3 \%)$ & $134(26.6 \%)$ & $75(14.9 \%)$ \\
\hline $\begin{array}{l}\text { I play games to help me cope with any bad feelings I might } \\
\text { have. }\end{array}$ & $80(15.9 \%)$ & $183(36.3 \%)$ & $77(15.3 \%)$ & $91(18.1 \%)$ & $73(14.5 \%)$ \\
\hline I never play games in order to feel better. & $56(11.1 \%)$ & $139(27.6 \%)$ & $149(29.6 \%)$ & $130(25.8 \%)$ & $30(6.0 \%)$ \\
\hline I play games to forget about whatever's bothering me & $77(15.3 \%)$ & $185(36.7 \%)$ & $75(14.9 \%)$ & $96(19 \%)$ & $71(14.1 \%)$ \\
\hline $\begin{array}{l}\text { I have significantly increased the amount of time I play games } \\
\text { over last year. }\end{array}$ & $79(15.7 \%)$ & $193(38.8 \%)$ & $68(13.5 \%)$ & $96(19 \%)$ & $68(13.5 \%)$ \\
\hline $\begin{array}{l}\text { I need to spend increasing amounts of time engaged in playing } \\
\text { games }\end{array}$ & $48(9.5 \%)$ & $177(35.1 \%)$ & $96(19 \%)$ & $133(26.4 \%)$ & $50(9.9 \%)$ \\
\hline $\begin{array}{l}\text { I often think that a whole day is not enough to do everything I } \\
\text { need to do in-game }\end{array}$ & $43(8.5 \%)$ & $85(16.9 \%)$ & $74(14.7 \%)$ & $189(37.5 \%)$ & $113(22.4 \%)$ \\
\hline When I am not gaming, I feel more irritable & $36(7.1 \%)$ & $77(15.3 \%)$ & $79(15.7 \%)$ & $171(33.9 \%)$ & $141(28.0 \%)$ \\
\hline I feel sad if I am not able to play games. & $22(4.4 \%)$ & $86(17.1 \%)$ & $92(18.3 \%)$ & $175(34.7 \%)$ & $129(25.6 \%)$ \\
\hline I tend to get anxious if I can't play games for any reason. & $27(5.4 \%)$ & $95(18.8 \%)$ & $76(15.1 \%)$ & $172(34.1 \%)$ & $134(26.6 \%)$ \\
\hline I have lost interest in other hobbies because of my gaming & $35(6.9 \%)$ & $142(28.2 \%)$ & $66(13.1 \%)$ & $159(31.5 \%)$ & $102(20.2 \%)$ \\
\hline $\begin{array}{l}\text { I have lied to my family members because the amount of gaming } \\
\text { I do }\end{array}$ & $36(7.1 \%)$ & $100(19.8 \%)$ & $61(12.1 \%)$ & $166(32.9 \%)$ & $141(28 \%)$ \\
\hline $\begin{array}{l}\text { I know my main daily activity (i.e., occupation, education, } \\
\text { homemaker, etc.) has not been negatively affected by my } \\
\text { gaming. }\end{array}$ & $60(11.9 \%)$ & $148(29.4 \%)$ & $74(14.7 \%)$ & $162(32.1 \%)$ & $60(11.9 \%)$ \\
\hline $\begin{array}{l}\text { I think my gaming has jeopardised the relationship with my } \\
\text { partner }\end{array}$ & $39(7.7 \%)$ & $96(19.0 \%)$ & $83(16.5 \%)$ & $161(31.9 \%)$ & $125(24.8 \%)$ \\
\hline $\begin{array}{l}\text { I believe my gaming is negatively impacting on important areas } \\
\text { of my life }\end{array}$ & $49(9.7 \%)$ & $166(32.9 \%)$ & $85(16.9 \%)$ & $123(24.4 \%)$ & $81(16.1 \%)$ \\
\hline I often try to play games less but find I cannot. & $58(11.5 \%)$ & $124(24.6 \%)$ & $101(20 \%)$ & $148(29.4 \%)$ & $73(14.5 \%)$ \\
\hline I do not think I could stop gaming. & $31(6.2 \%)$ & $129(25.6 \%)$ & $95(18.8 \%)$ & $163(32.3 \%)$ & $86(17.1 \%)$ \\
\hline I often try to play games less but find I cannot. & $36(7.1 \%)$ & $119(23.6 \%)$ & $93(18.5 \%)$ & $166(32.9 \%)$ & $90(17.9 \%)$ \\
\hline
\end{tabular}

Participants completed an Arabic translated version of the IGD-20 tool (Table 3), measuring six aspects of behavioural addiction: 'Salience', 'Mood Modification', 'Tolerance', and 'Withdrawal Symptoms', 'Conflict', and 'Relapse'. Most gamers $(44.1 \%, \mathrm{n}=222)$ denied losing sleep because of long gaming sessions. However, the majority $(46.2 \%, \mathrm{n}=233)$ stated that gaming has become the most time-consuming activity in their daily life. Over half of the participants $(52.5 \%, n=263)$ said that they played games to help them cope with any bad feelings they might have or to forget about whatever is bothering them $(52 \%, \mathrm{n}=262)$. On the contrary, around $38.7 \%$ $(n=195)$ of the participants claimed they never play games to feel better.

About $22.4 \%(n=113)$ of gamers reported feeling irritable when not playing. Similarly, $21.5 \%(\mathrm{n}=108)$ and $24.2 \%$ $(n=122)$ of participants reported feeling sad or anxious if they were unable to play games, respectively. Most participants $(42.6 \%, \mathrm{n}=215)$ agreed that gaming is negatively affecting important areas in their lives. Likewise, the majority of participants $(43 \%, n=222)$ believed that gaming has negative impacts on their daily activities, such as work, education, or household tasks. When asked if they believed they could stop gaming, most participants $(49.4 \%, \mathrm{n}=249)$ agreed, while around $31.8 \%(n=160)$ disagreed. About $30.7 \%$ also reported being unable to reduce gaming duration despite trying. In fact, over half of gamers $(54.5 \%, \mathrm{n}=272)$ stated they have significantly increased the amount of gaming time over only the last year.

\section{DISCUSSION}

In this study, the majority of gamers were males, although there were no significant differences by gender in being a 
disordered or non-disordered player. Students constituted the majority of participants, although unemployed gamers played for more hours in total. Gender and device type were also factors associated with the number of hours played per week.

Disordered gamers comprised 96 out of our 504 players study population, making the prevalence of IGD among gamers around $19 \%$. Comparably, prevalence rates previously reported in literature ranged from as low as $0.6 \%$ to as high as $8.5 \%$, with higher rates in Asian countries and among male adolescents $[2,8]$. However, one should bear in mind that most of these studies measured IGD in general populations such as university students and internet users. Therefore, the high prevalence reported in this study can be justified by the restriction of enrolment to gamers only. Indeed, a study from Singapore examining IGD among internet game players reported a similar percent of $17.7 \%$ disordered gamers [18]. The profile of IGD patients was also comparable to the one obtained in our study, as most disordered gamers were of primary to secondary education and were current students [18]. Another study with a 1420 gamers population showed a $3.6 \%-44 \%$ prevalence of addicted gamers [19]. In accordance with current results, time spent playing per week significantly correlated with online gaming addiction [20]. This was further confirmed by results from India, where time spent playing, in addition to greater depressive symptoms and a preference of multiplayer online gaming were all strongly predictive of gaming disorders [20]. A report from King et al. shows that as the time invested in playing increases, gamers receive more motivations for playing more, such as status among gamers and collecting game rewards [21]. This may justify the strong correlation between total gaming time and IGD; it especially reflects the tolerance aspect of the addiction. In fact, over half of gamers $(54.5 \%)$ in our study stated they have significantly increased the amount of gaming time over only the last year. Other aspects reflecting addictive behaviour were also recognized among participants to varying extents, including withdrawal, conflict, and relapse.

In addition to total playing time per week, predictors of IGD in this study included educational level. Gamers acquiring up to secondary education were the most disordered, while post-graduates constituted only $8.3 \%$ of disordered gamers. This agrees with another study investigating IGD among international female gamers, where education was highly predictive of IGD. This study also showed correlation between the type of occupation and developing IGD, as unemployed gamers had the highest IGD scores [22]. Other studies have also reported higher IGD scores among those with more free time to invest in playing $[23,24]$. However, the current study finds no significant association between IGD and occupation, with unemployed gamers constituting only $13 \%$ of disordered patients, despite investing more hours in gaming.

IGD is widely regarded as a 'man's disease', with a large study showing that $11.9 \%$ of males were diagnosed with IGD compared to $2.9 \%$ females [25]. These gender-based differences may be because more gamers in general are males. Indeed, in the current study, males constituted the majority of gamers 348 (69\%). This may be due to several factors. Firstly, the design of online and video games predominantly draws attention and satisfies the needs of males in a male-dominant gaming industry [26]. Moreover, females do not conform to typical gamer stereotypes, often perceived asmasculine, leading to stigmatization of female gamers by the gaming community [27]. This is further perpetuated by the over-sexualization of female avatars, reflecting an objectification of women in these games [28]. Despite that, IGD is increasingly being diagnosed among females $[1,25]$. In the current study, gender was associated with playing hours per week, as males were more likely to spend more hours playing than females ( $P$ value $<0.005$ ). However, no association was found between gender and addictive gaming. Two other studies agreed with these results, where gender was not a significant predictor of game addiction $[9,29]$. Therefore, perception of IGD as a disease of males may limit diagnosis in females, who may show different characteristics of the disease [22, 30].

Devices used for gaming among participants, in the current study, varied between smartphones, a personal computer, a video game console such as PlayStation or Xbox, and tablets. Despite smartphones being the most used device for playing, those who played using computers spent the highest hours per week playing. A previous study has investigated gaming patterns across different devices [31]. Combined users of smartphones and computer games appeared to be more at risk of developing IGD and other psychological disorders. Meanwhile, the lowest prevalence of IGD was seen among smartphone users. Another study found a correlation between online games and IGD [32]. The study compared online and offline games among a sample of disordered and nondisordered players. Disordered players were found to spend three to four times as much time as non-disordered gamers playing online games.

The current study has a few limitations. Firstly, the questionnaire-based strategy may subject responses to recruitment and recall biases. Means to verify information regarding age and other demographics were also lacking due to online recruitment, creating a chance for misreports. Notably, the results of the current study were generally consistent with previous studies from other populations. Moreover, questionnaires represent the basis for most IGD studies, proving consistently as a successful method for this type of research. The relatively small sample size may also limit the ability of this study to detect differences in the prevalence of IGD between genders. Furthermore, the current study used convenient rather than random sampling as the study targeted internet gamers as its population, where means for taking a random sample from this group is not present as there is no official listing for internet gamers.

\section{CONCLUSION}

Following the inclusion of internet gaming disorder (IGD) in the fifth edition of the Diagnostic and Statistical Manual of Mental Disorders (DSM-5), IGD became a subject of concern in internet game users. Since then, various studies have attempted to create a profile for gamers from both genders, and among different geographical areas. Our study shows a predominance of male gamers, albeit with no difference in game addiction compared to females. Total time spent gaming 
per week and educational level were the strongest predictors of IGD, while employment and device type predicted time spent playing. More research is recommended to understand disordered gamer profile in greater detail, especially in understudies populations such as females.

\section{LIST OF ABBREVIATIONS}

$$
\begin{array}{lll}
\text { DSM-5 } & =\text { Diagnostic and Statistical Manual of Mental } \\
& \text { Disorders Fifth Edition } \\
\text { IGD } & =\text { Internet Gaming Disorder } \\
\text { ICD-11 } & =\text { International Classification of Diseases } \\
\text { MMORPGs }= & \text { Massively Multiplayer Online Role-Playing Games } \\
\text { DSM-IV-TR }= & \text { Diagnostic and Statistical Manual of Mental } \\
& \text { Disorder fourth revised edition } \\
\text { GIAD } & =\text { Goldberg Internet Addiction Disorder scale } \\
\text { ISS } & =\text { Internet Stress Scale } \\
\text { ETHICS APPROVAL AND CONSENT TO } & \text { TO } \\
\text { PARTICIPATE }
\end{array}
$$

\section{ETHICS APPROVAL AND CONSENT TO PARTICIPATE}

The ethical approval for conducting the study was obtained from the Institutional Review Board (reference code $32 / 119 / 2018)$.

\section{HUMAN AND ANIMAL RIGHTS}

No animals were used for studies that are base of this research. All the humans used were in accordance with the ethical standards of the committee responsible for human experimentation (institutional and national), and with the Helsinki Declaration of 1975, as revised in 2013.

\section{CONSENT FOR PUBLICATION}

Written informed consent was obtained from each participant prior to the study for publication of this research.

\section{STANDARDS OF REPORTING}

STROBE guidelines and methodolog were followed.

\section{AVAILABILITY OF DATA AND MATERIALS}

The data supporting the findings of the article is available from corresponding author [S.A.-A] upon reasonable request.

\section{FUNDING}

This work was supported by the Deanship of Scientific Research at Yarmouk University (grant number 46/2018). The funders had no role in study design, data collection and analysis, decision to publish, or preparation of the manuscript.

\section{CONFLICT OF INTEREST}

The authors declare no conflict of interest, financial or otherwise.

\section{ACKNOWLEDGEMENTS}

Declared none.

\section{REFERENCES}

[1] APA. American Psychiatric Association, 2013 Diagnostic and statistical manual of mental disorders. $5^{\text {th }}$ ed. 2013. [http://dx.doi.org/10.1176/appi.books.9780890425596.744053]

[2] Paulus FW, Ohmann S, von Gontard A, Popow C. Internet gaming disorder in children and adolescents: A systematic review. Dev Med Child Neurol 2018; 60(7): 645-59.

[http://dx.doi.org/10.1111/dmcn.13754] [PMID: 29633243]

[3] Wartberg L, Kriston L, Thomasius R. The prevalence and psychosocial correlates of internet gaming disorder. Dtsch Arztebl Int 2017; 114(25): 419-24.

[http://dx.doi.org/10.3238/arztebl.2017.0419] [PMID: 28683852]

[4] Gentile DA, Choo H, Liau A, et al. Pathological video game use among youths: A two-year longitudinal study. Pediatrics 2011; 127(2): e319-29.

[http://dx.doi.org/10.1542/peds.2010-1353] [PMID: 21242221]

[5] American Psychiatric Association. Diagnostic and statistical manual of mental disorders. $5^{\text {th }}$ ed. Arlington, VA: American Psychiatric Association Publishing 2013.

[http://dx.doi.org/10.1176/appi.books.9780890425596]

[6] Higuchi S, Nakayama H, Mihara S, Maezono M, Kitayuguchi T, Hashimoto $T$. Inclusion of gaming disorder criteria in ICD-11: A clinical perspective in favor. J Behav Addict 2017; 6(3): 293-5. [http://dx.doi.org/10.1556/2006.6.2017.049] [PMID: 28816497]

[7] Kuss DJ, Griffiths MD, Karila L, Billieux J. Internet addiction: A systematic review of epidemiological research for the last decade. Curr Pharm Des 2014; 20(25): 4026-52.

[http://dx.doi.org/10.2174/13816128113199990617] [PMID: 24001297]

[8] Pontes HM, Király O, Demetrovics Z, Griffiths MD. The conceptualisation and measurement of DSM-5 Internet Gaming Disorder: The development of the IGD-20 Test. PLoS One 2014; 9(10)e110137

[http://dx.doi.org/10.1371/journal.pone.0110137] [PMID: 25313515]

[9] Festl R, Scharkow M, Quandt T. Problematic computer game use among adolescents, younger and older adults. Addiction 2013; 108(3): 592-9.

[http://dx.doi.org/10.1111/add.12016] [PMID: 23078146]

[10] Gentile D. Pathological video-game use among youth ages 8 to 18: A national study. Psychol Sci 2009; 20(5): 594-602.

[http://dx.doi.org/10.1111/j.1467-9280.2009.02340.x] [PMID: 19476590]

[11] Hur MH. Demographic, habitual, and socioeconomic determinants of Internet addiction disorder: An empirical study of Korean teenagers. Cyberpsychol Behav 2006; 9(5): 514-25.

[http://dx.doi.org/10.1089/cpb.2006.9.514] [PMID: 17034317]

[12] Fam JY. Prevalence of internet gaming disorder in adolescents: A meta-analysis across three decades. Scand J Psychol 2018; 59(5): 524-31.

[http://dx.doi.org/10.1111/sjop.12459] [PMID: 30004118]

[13] Müller KW, Janikian M, Dreier M, et al. Regular gaming behavior and internet gaming disorder in European adolescents: results from a crossnational representative survey of prevalence, predictors, and psychopathological correlates. Eur Child Adolesc Psychiatry 2015; 24(5): 565-74.

[http://dx.doi.org/10.1007/s00787-014-0611-2] [PMID: 25189795]

[14] Ko C-H, Yen J-Y, Chen C-C, Chen S-H, Yen C-F. Gender differences and related factors affecting online gaming addiction among Taiwanese adolescents. J Nerv Ment Dis 2005; 193(4): 273-7. [http://dx.doi.org/10.1097/01.nmd.0000158373.85150.57] [PMID: 15805824]

[15] Rehbein F, Kleimann M, Mössle T. Prevalence and risk factors of video game dependency in adolescence: results of a German nationwide survey. Cyberpsychol Behav Soc Netw 2010; 13(3): 269-77.

[http://dx.doi.org/10.1089/cyber.2009.0227] [PMID: 20557246]

[16] Donati MA, Chiesi F, Ammannato G, Primi C. Versatility and addiction in gaming: the number of video-game genres played is associated with pathological gaming in male adolescents. Cyberpsychol Behav Soc Netw 2015; 18(2): 129-32. [http://dx.doi.org/10.1089/cyber.2014.0342] [PMID: 25684613]

[17] Mihara S, Higuchi S. Cross-sectional and longitudinal epidemiological studies of Internet gaming disorder: A systematic review of the literature. Psychiatry Clin Neurosci 2017; 71(7): 425-44. 
[http://dx.doi.org/10.1111/pcn.12532] [PMID: 28436212]

[18] Subramaniam M, Chua BY, Abdin E, et al. Prevalence and correlates of internet gaming problem among internet users: Results from an internet survey. Ann Acad Med Singap 2016; 45(5): 174-83. [PMID: 27383716]

[19] Hussain Z, Griffiths MD, Baguley T. Online gaming addiction: Classification, prediction and associated risk factors. Addict Res Theory 2012; 20(5): 359-71.

[http://dx.doi.org/10.3109/16066359.2011.640442]

[20] Singh S, Dahiya N, Singh AB, Kumar R, Balhara YPS. Gaming disorder among medical college students from India: Exploring the pattern and correlates. Ind Psychiatry J 2019; 28(1): 107-14. [http://dx.doi.org/10.4103/ipj.ipj_96_18] [PMID: 31879456]

[21] King DL, Herd MCE, Delfabbro PH. Tolerance in Internet gaming disorder: A need for increasing gaming time or something else? J Behav Addict 2017; 6(4): 525-33.

[http://dx.doi.org/10.1556/2006.6.2017.072] [PMID: 29137493]

[22] Lopez-Fernandez O, Williams AJ, Kuss DJ. Measuring female gaming: Gamer profile, predictors, prevalence, and characteristics from psychological and gender perspectives. Front Psychol 2019; 10: 898.

[http://dx.doi.org/10.3389/fpsyg.2019.00898] [PMID: 31105622]

[23] Seok S, Dacosta B. The world's most intense online gaming culture: Addiction and high-engagement prevalence rates among South Korean adolescents and young adults. Comput Human Behav 2012. [http://dx.doi.org/10.1016/j.chb.2012.06.019]

[24] Lopez-Fernandez O. Generalised versus specific internet use-related addiction problems: A mixed methods study on internet, gaming, and social networking behaviours. Int J Environ Res Public Health 2018; 15(12): E2913.

[http://dx.doi.org/10.3390/ijerph15122913] [PMID: 30572652]

[25] Gentile D. Pathological video-game use among youth ages 8 to 18: A national study. Psychol Sci 2009; 20(5): 594-602. [http://dx.doi.org/10.1111/j.1467-9280.2009.02340.x]

[PMID: 19476590

[26] Kuss DJ, Griffiths MD. Internet gaming addiction: A systematic review of empirical research. Int J Ment Health Addict 2012.

[http://dx.doi.org/10.1007/s11469-011-9318-5]

[27] Paaßen B, Morgenroth T, Stratemeyer M. What is a true gamer? The male gamer stereotype and the marginalization of women in video game culture. Sex Roles 2017; 76(7): 421-35.

[http://dx.doi.org/10.1007/s11199-016-0678-y]

[28] Lynch T, Tompkins JE, van Driel II, Fritz N. Sexy, strong, and secondary: A content analysis of female characters in video games across 31 years. J Commun 2016; 66(4): 564-84.

[http://dx.doi.org/10.1111/jcom.12237]

[29] Dreier M, Wölfling K, Duven E, Giralt S, Beutel ME, Müller KW. Free-to-play: About addicted whales, at risk dolphins and healthy minnows. monetarization design and internet gaming disorder. Addict Behav 2017; 64: 328-33.

[http://dx.doi.org/10.1016/j.addbeh.2016.03.008] [PMID: 27178749]

[30] González-Bueso V, Santamaría JJ, Merino L, Montero E, Cano-Vega M, López-Fernández O. Psychopathological differences in women with Emotional Dependence with and without the use of illegal substances comorbid, Quad. Med Psychosomatics and Psychiatrist Link 2016

[31] Paik SH, Cho H, Chun JW, Jeong JE, Kim DJ. Gaming device usage patterns predict internet gaming disorder: Comparison across different gaming device usage patterns. Int J Environ Res Public Health 2017; 14(12): E1512.

[http://dx.doi.org/10.3390/ijerph14121512] [PMID: 29206183]

[32] Lemmens JS, Hendriks SJF. Addictive online games: Examining the relationship between game genres and internet gaming disorder. Cyberpsychol Behav Soc Netw 2016; 19(4): 270-6. [http://dx.doi.org/10.1089/cyber.2015.0415] [PMID: 26959285]

\section{C) 2021 Karasneh et al.}

This is an open access article distributed under the terms of the Creative Commons Attribution 4.0 International Public License (CC-BY 4.0), a copy of which is available at: https://creativecommons.org/licenses/by/4.0/legalcode. This license permits unrestricted use, distribution, and reproduction in any medium, provided the original author and source are credited. 